\title{
NARRATIVAS SOBRE PROSTITUIÇÃO NO ACRE TERRITÓRIO (1904-1920) ${ }^{1}$
}

\author{
NARRATIVES ON PROSTITUTION IN ACRE TERRITORY (1904- \\ 1920)
}

Altaíza Liane Marinho ${ }^{2}$

\section{RESUMO}

Com este artigo procura-se apresentar uma abordagem acerca de narrativas sobre prostituição no Território Federal do Acre, entre os anos 1904-1920, no contexto da inserção dessa parte da Amazônia como integrante do território brasileiro. Ao abordar o espaço-tempo de circulação de tais narrativas, tem-se o propósito de situar o leitor sobre seu lugar de produção e "maneiras de escrever" o "outro", nesse caso, a "outra", a partir de artigos e notícias publicadas nos jornais Folba do Acre e Commercio do Acre. Como parte da abordagem entra em discussão aspectos relacionados à perspectiva histórica na relação linguagem e identidade, sob inspiração dos estudos de Jorge Larrosa, Margareth Rago e Roger Chartier.

\section{PALAVRAS-CHAVE}

Amazônia acreana. Narrativas. Identidade. Prostituição. Cultura.

\section{ABSTRACT}

This article intends to present an analysis on the narratives about prostitution in Acre during the period of Federal Territory, between 1904 and 1920, in the context of the insertion of this part of the Amazon as constituent of the Brazilian territory. In addressing the space-time of circulation of such narratives, this paper intends to situate the reader on its place of production and "ways of

\footnotetext{
1 Versão alterada de texto originalmente apresentado como parte da Dissertação de Mestrado "Narrativas de papoucos, siribolos e pontapés: representações sobre prostituição em periódicos de Rio Branco", defendida no ano de 2016, junto ao Programa de Pós-Graduação em Letras: Linguagem e Identidade da Universidade Federal do Acre, sob a orientação do Professor Dr. Francisco Bento da Silva.

2 Mestra em Letras: Linguagem e Identidade pela UFAC e Professora substituta do Instituto Federal de Educação, Ciência e Tecnologia do Acre - IFAC 2016/2018 e membro do Núcleo de Estudos Afro-Brasileiros e Indígenas - NEABI.
} 
writing" the "other", in this case, the "female other", from articles and news published in the newspapers Folha do Acre and Commercio do Acre. As part of the approach, aspects related to the historical perspective in the relation between language and identity, which are discussed under the inspiration of the studies of Jorge Larrosa, Margareth Rago and Roger Chartier.

\section{KEYWORDS}

Acre Amazon. Narratives. Identity. Prostitution. Culture.

Parece-me que pensar de outro modo é escrever de outro modo, e que escrever de outro modo requer ler de outro modo (e sobretudo ler outras coisas). (Jorge Larrosa)

Parece-nos que o convite feito pelo espanhol Jorge Larrosa, que implica diretamente em uma proposta de se pensar, escrever e ler de outro modo requer fundamentalmente mover-se entre os planos movediços da linguagem. Essa proposta inicial (sobre linguagem) parte de inquietações resultantes de processos que outrora resistiam em sua maior potencialidade, em uma multiplicidade de questões "não resolvidas" sobre as palavras e os sentidos dados a elas, enquanto objeto de manipulação, controle e poder (LARROSA, 2014, p. 295).

A linguagem vista por essa ótica e como elemento das relações de poder, subscrita na lógica em que nos é dada a pensar, a escrever e a ler, justifica o interesse advertido por Larrosa sobre as "lutas pelas palavras, pelo significado e pelo controle das palavras, pela imposição de certas palavras e pelo silenciamento ou desativação de outras, são lutas em que se joga algo mais que simplesmente palavras, algo mais que somente palavras" (LARROSA, 2014, p. 153). Advertência esta que nos faz refletir não simplesmente a partir do jogo das palavras, mas substancialmente sobre os significados e significações em decorrência do vasto campo da linguagem, enquanto portadora de discursos, de imagens, de signos e de símbolos.

Nessa perspectiva, a partir dessa leitura e entendendo que os espaços são constituídos pela linguagem e na linguagem (e aqui remetemos a espaços sociais, culturais e ideológicos), mantemos e compartilhamos a sugestiva proposta de Larrosa, entrelaçando-a em todo o percurso deste artigo, que se faz a partir da proposta de repensar e lançar outro olhar ao 
sentido dado às narrativas de prostituição dos jornais Folha do Acre e Commercio do Acre, que estiveram em circulação no início do século XX, mais propriamente no Acre Território (1904 a 1920).

A reflexão sobre o Território Federal do Acre leva a questionar sobre como a Amazônia acreana estava organizada no início do século XX. Sob qual perspectiva o Território do Acre era visto, lido, pensado e dado a ler? Na história "oficial", encontramos alguns vestígios de um espaço politicamente organizado a partir de 1904, sob o nome de Território Federal do Acre, por determinação do Decreto no 5.188 , de 7 de abril de 1904. Logo, o Território do Acre passa a ser organizado da seguinte forma: "Departamento do Alto Acre (com sede em Rio Branco); Departamento do Alto Purus (com sede em Sena Madureira); Departamento do Alto Juruá (com sede em Cruzeiro do Sul); Departamento do Alto Tarauacá (com sede em Tarauacá)" (COSTA, 1973, pp. 136-137).

A historiografia "oficial" destaca em cada Departamento uma administração exercida por prefeitos, nomeados diretamente pelo governo federal sendo "Juruá e Tarauacá, Purus e Acre, geograficamente, regiões separadas pela natureza; entre elas o labirinto hidrográfico e a espessura da floresta, levantando a muralha da separação". Segundo João Craveiro Costa, a Administração do Território Federal do Acre, "foi entregue, discricionariamente, a autoridades denominadas prefeitos em número de três, que tantas foram as circunscrições administrativas criadas, nomeados pelo presidente da Republica, militares todos, sem limitação para a sua esfera governamental" (COSTA, 1973, pp. 138-139).

Dessa maneira, observamos que os prefeitos enviados ao Território do Acre tinham como atribuição organizar e administrar os Departamentos, e curiosamente passavam a ser a maior autoridade local, tendo em vista que, na prática, o prefeito controlava e encampava os poderes legislativo, executivo, de policia e às vezes até o judiciário. Apesar de enfeixarem amplos poderes na administração dos Departamentos, pouco ou quase nada foi feito nesse período, como relata Costa no livro A conquista do deserto ocidental: subsídios para a história do Território do Acre:

No Território do Acre tudo estava por fazer, porque nunca nele se fizera sentir a ação protetora de um governo. Apesar disso, a organização não 
cuidou do saneamento da região, então considerado pelo exagero da nossa ignorância a antecâmara da morte; da desobstrução facílima de seus rios principais, tornando-se esses imensos cursos fluviais as verdadeiras estradas do progresso acreano; do direito de propriedade às magníficas terras, quase todas, as marginais, habilitadas e na posse particular de muitos anos; da abertura de vias terrestres que facilitassem a ação do governo que se iniciava e estabelecessem relações de comércio e de a sociedade entre as populações dos dois vales; de medidas que amparassem a indústria extrativa da borracha, dando-lhe outra orientação e assegurando-lhe o futuro contra o perigo da concorrência asiática, que já se desenhava nitidamente, de providências, enfim, que acelerassem o desenvolvimento econômico do novo patrimônio nacional, pela cultura da terra e abertura de campos pastoris, pela exploração de suas vastas riquezas naturais acumuladas nas aguas, no solo e nas florestas. Nada se fez nesse sentido (COSTA, 1973, p. 139).

A partir dessa descrição, observamos que o autor faz referência a um espaço à mercê da organização da estrutura pública. Através dessa descrição, considerando-se ou não a veracidade do relato, podemos obter uma representação do Território Federal do Acre, que pode ajudar na imagem refletida da Amazônia acreana na época, constituída pela falta de "saneamento", de "vias terrestres", de medidas de apoio à "indústria extrativista", ao "desenvolvimento econômico", à "cultura da terra" e às "riquezas naturais". Tal representação nos direciona, de maneira tendenciosa, a imaginar um lugar "abandonado", sobretudo se levarmos em consideração o modelo de estrutura do espaço público, um espaço não urbanizado e sem vestígios de "civilização".

Logo, o espaço da cidade e o ordenamento/reordenamento social (que, por sinal, caminham lado a lado, mas sempre acompanhados do discurso da "necessidade" de um novo re/ordenamento dos espaços) passam a ser alvo das administrações departamentais. Nesse contexto do início do século XX, encontramos um espaço urbano caracterizado a partir da necessidade da "modernidade" e do "moderno", passando a ser entendido e construído pela ascensão dos espaços de sociabilidade. Isso se aplica em nível nacional, onde espaços urbanos são projetados a partir das imagens atribuídas às cidades europeias. Assim, o primeiro palco da avassaladora transformação urbanística, em fins do século XIX, foi a cidade do Rio de Janeiro, então a capital da república brasileira. Nesse 
contexto, temos uma maior preocupação com dois fatores característicos do período supracitado: o espaço urbano e a sanitarização.

A higiene pública, pensada pelo governo brasileiro, indica alguns fatores a serem analisados, como, por exemplo, as práticas das autoridades militares, ou melhor, o ordenamento político que era aplicado diretamente pelos militares. Em alguns casos, os registros históricos contrariamente apresentamesse ordenamento comomodelode "benfeitorias", "melhorias", "progresso", "civilização" e "modernidade" do espaço público; e nada mais se acrescenta a isso, a não ser o fato de não considerarmos uma realidade plena o que tem sido dito através da historiografia sobre as tais "benfeitorias" do governo brasileiro.

Como destaca Menezes:

Para a Capital Federal buscaram-se outras representações que não aquelas das grandes mortandades ocasionadas pelas epidemias; dos carregadores descalços e sem camisa; dos ambulantes, aos gritos, percorrendo a cidade; do ruído dos tamancos no vaivém das ruas; do odor do bacalhau e do toucinho de fumeiro pendurados nos armazéns de secos e molhados; dos capoeiras desafiando a ordem e glorificando a vadiagem. Os primeiros anos do século foram marcados pela importação de produtos e homens, usos e costumes, fazeres e lazeres, crimes e contravenções, valores e visões de mundo. Romper com a tradição urbana colonial, caracterizada pela indiferenciação espacial e pela promiscuidade social nas ruas, foi um desafio que a jovem república se propôs numa espécie de cidade- modelo, destinada a atrair o capital estrangeiro e garantir às elites um viver civilizado (MENEZES, 1996, p. 31).

Reduzir tais questões ao silêncio ou mesmo não questioná-las não seria a melhor maneira de lidar com as representações materiais e simbólicas das cidades, dos espaços, dos lugares, e dos sujeitos. Nessa direção, a leitura feita a partir das "grandes mudanças" que o novo regime político trouxe consigo, afetando diretamente os sujeitos desses espaços, faz despertar o interesse de estudar mais a fundo esse "novo" processo de "modernidade", aplicado primeiramente na capital republicana, o Rio de Janeiro, que se tornou alvo das implicações desse fenômeno. Implicações tais que refletiram diretamente na administração organizacional dos Departamentos do Território Federal do Acre, mais propriamente no processo de "urbanização" e disciplinarização dos espaços amazônicos.

O que veio junto com a "modernização" da capital como modelo a 
ser seguido pelos demais espaços/lugares da república? De maneira mais categórica, a garantia do "progresso" implicou em quais transformações sociais? Estamos falando de um "progresso" que refletia "realidades diferenciadas para vários segmentos sociais que o vivenciavam, traduzido não só na importação de produtos e técnicas, mas também de homens, comportamentos, valores e ideias variadas" (MENEZES, 1996, p. 29).

Dessa forma, lentamente nos são apresentadas as implicações de tais configurações, de modo que, frente ao projeto urbanístico, "o novo e o moderno abriam caminho numa voracidade sem limites, que tragava morros, mar, construções e todo um ser e sentir, no irreversível processo de edificação da nova capital, vitrine do novo regime" (MENEZES, 1996, p. 27). Simultaneamente, os rastros de "urbanização" são deixados impiedosamente, conforme destaca Menezes:

Beleza, saneamento e racionalidade tornaram-se lemas dos novos tempos. Recurso e esforços foram canalizados no sentido de apagar os traços coloniais presentes nas ruas estreitas com valas centrais; nos becos mal iluminados, mal cheirosos e afamados; nos cortiços e estalagens que proliferavam no coração da Cidade Velha; nas mercadorias e quiosques sujos das áreas de circulação, nos armazéns de secos e molhados das vias centrais, que pareciam afrontar os que aplaudiam a chegada da civilização (MENEZES, 1996, p. 28).

A partir das medidas tomadas, novos indícios surgem de uma transformação inovadora que, "ocasionalmente", "reprimiram os costumes tradicionais, esconderam a pobreza e os vícios na periferia, e procuraram manter sob vigilância e controle as vozes discordantes no conjunto dos excluídos” (MENEZES, 1996, p. 29). Os “indesejáveis”, termo empregado por Menezes em seu livro, passam a ser objeto de perseguição do governo federal, pois os espaços são criados historicamente a partir das percepções dos seus ocupantes, ou seja, transformar o espaço urbano requer uma transformação dos seus sujeitos; e isso implica nas questões das normas, das regras, e das disciplinas. Nessa perspectiva, é acarretada também a "limpeza social" desses espaços.

"Becos", "cortiços", "quarteirões", "ruas" e "vilarejos", todo e qualquer ambiente fez parte do avassalador processo de "urbanização" do início do século XX com seu consequente "o processo de imposição da disciplina nas ruas, na prática, consistiu no afastamento de vadios, 


\section{ARTIGO}

desordeiros, mendigos, prostitutas, caftens e trabalhadores, nos horários fora do expediente, das vias públicas: um projeto disciplinar conduzido pelas instituições policiais” (MENEZES, 1996, p. 38).

É nesse cenário que os poderes públicos visualizam as estratégias sanitaristas, que em sua totalidade constituem um projeto de desodorização dos espaços, quase como um o projeto estético das cidades. Assim, as autoridades começam a associar as medidas higiênicas à desinfecção dos espaços:

$[\mathrm{O}] \mathrm{s}$ médicos higienistas, portanto, percebem-se como as autoridades necessárias e competentes para vistoriar minuciosamente a habitação e os bairros populares, incentivando o asseio e impondo autoritariamente a execução de medidas higiênicas. O controle global da população pobre da cidade, seja nos lugares públicos, seja no espaço doméstico, por parte destes especialistas se funda na crença generalizada de que a "casa imunda", o cortiço e a favela constituem focos onde se originam os surtos epidêmicos, os vícios e os sentimentos de revolta. E o mal deve ser extirpado pela raiz (RAGO, 1985, p. 164).

Segundo Menezes, até 1930 a cidade do Rio de Janeiro mudou completamente sua imagem. E todo esse processo urbanístico na cena pública, iniciado ainda no final do século XIX, implicou diretamente no afastamento dos “indesejados” para as regiões da Amazônia no início do século XX (apudSILVA, 2013). Nessa época, não diferentemente da capital federal, podemos visualizar representações semelhantes no Território Federal do Acre sobre um futuro e um "progresso" visto apenas pelas autoridades. De acordo com o relato do jornal Folha do Acre, intitulado "Pela moralidade publica", observamos a construção de uma cidade imaginada, que se fazia a partir de percepções idealizadas:

É este um dos assumptos que muito nos preocupam em relação á Empreza. Desejaríamos vél-a, apar do progresso material e intelectual que nella se desenvolve dum modo assás esperançoso, impor-se numa afirmação de respeito a acatamento aos sagrados princípios da moral e do decôro social. Se a prosperidade no commercio, na indústria, em todos os ramos da atividade humana descobra uma prodigiosa série de vantagens á fácil acquisição da fortuna, multiplicando os benefícios áquelles que já a possuem; se as conquistas da inteligência, tendo por base a instrucção, felicitam e engrandecem uma sociedade, aureolando-a de glórias e dando-lhe no conceito universal um renome brilhante e perdurador, - a moral, synthese, sociaes e 
domesticas, assegura ao povo que observa os seus dictames e seus preceitos a conservão da felicidade que ambiciona. Eis porque dentre os problemas de que cogitamos no empenho de vermos o Acre, prospero e respeitado, se impor a consideração da paiz, ocupa um logar saliente o que diz respeito ao assumpto expresso pelo titulo a que subordinamos estas linhas. $\mathrm{Na}$ Empreza, onde tudo parece avançar para um futuro repleto de venturas, e em cujo horizonte o sol da civilisação, rasgando as espessas brumas de atrazo primitivo com os sacrifícios dos seus filhos, despontou pondo em notável relevo uma sociedade de homens capazes de concorrer para o engradecimento da pátria a que se desvanecem de pertencer; nesta cidade nova e esperançosa urge que brilhe com a mesma intensidade a luz duma moral pura a que todos rendam a mais escrupulosa homenagem. Não queremos dizer com isso que aqui não se saibam ainda acatar os princípios dessa excelente e magna virtude; não queremos dizer, pois isso seria externar uma inverdade e até uma afronta à nossa sociedade, que aqui não se pratique o respeito ás leis da moral. Não, na Empreza há uma sociedade compenetrada dos seus deveres, sem embargo da sua recente formação (FOLHA DO ACRE, 20/9/1910, pp.1-2).

Notadamente, as comoventes palavras do editorial, que de forma rotineira se contradizem, expressam em grande parte do texto um discurso peculiar observado nos outros jornais analisados em todo o processo da pesquisa. $\mathrm{Na}$ intenção de agradar a todo o público alvo, o jornal violentamente "agride" seus leitores. Emerge das palavras do editorial, primeiramente, uma sutileza ao expressar o desejo de "progresso material e intelectual" que, em Empreza, ora externava e ora cogitava-se longe da civilização, da mesma maneira que dizia ser uma "inverdade" afirmar tal "afronta" a sua sociedade.

Observemos ainda o reforço dado à matéria, que muito se aproximava de uma "denúncia", descrita nas considerações do editorial da Folha do Acre:

Mas, não desconhecemos os abusos que se perpretam em nossas ruas, seja isso embora a consequência inevitável das imperfeições ainda não sanadas e próprias das cidades cujas organizações ainda se resentem dos necessários complementos que demandam muito tempo e muito trabalho, ou seja o defeito da má educação de certos typos levianos por cujo procedimento não se póde responsabilizar a sociedade que o recebe como uma afronta e o repelle como uma indignidade (...). Temos assistido, nas ruas mais concorridas da nossa cidade a scenas bem dignas da intervenção policial. É justo, porem, declinarmos aqui das autoridades incumbidas desse ramo administrativo, um pouco das responsabilidades desses factos, porquanto reconhecemos que actualmente não dispõem ellas de elementos para um serviço completo de 
policiamento. A nossa guarda-local é deficiente para esse serviço e não póde, portanto, corresponder ás exigências do mesmo. Há apenas um delegado auxiliar que por melhor boa vontade que tenha, não póde distribuir a sua actividade a todos os pontos onde a assistência da autoridade se faz necessária. Ao menos, porém, no centro da cidade, nos logares mais públicos a nossa policia deve reprimir os abusos, evitando os escândalos a que temos que assistir, embora tenha de dedicar a maior parte de sua vigilância e do seu tempo a esse trabalho. E deante de tão grave e inadiável necessidade, urge que a nossa polícia seja dotada de melhoramentos compatíveis com as exigências da missão a seu cargo, afim de que não tenhamos o desprazer de ver continuar a nossa cidade franqueada ás tropelias dos mal-educados e dos lustriões pouco escrupulosos, com esgares de engraçados e democratas. Quanto à fadistagem luarenta e despudorosa, aos proselytos duma facúndia irritantes e inimigo da decência e da compostura que todo homem deve manter, aos adoradores enflusiastas de Baccho, aos partidários do eynismo, quando em flagrante exhibição de suas proezas e graças, a uns deve ser concedido o hibernáculo xilindróense que os resguarde da humidade da noite, e a outros o refrigério do calmante policial que abrande o ardor das suas cálidas evaporações e apague as chamas dos seus arrojos (FOLHA DO ACRE, 20/9/1910, pp.1-2).

A narrativa "Pela moralidade pública" nos desperta questões imprescindíveis para o diálogo ao qual nos propomos daqui por diante: pensar as imagens de um lugar e dos seus sujeitos, dentro da percepção representativa em que é dado a ver, a ler, e entender. O noticiário nos dá uma dimensão da situação em que se encontrava o Território Federal do Acre, mais especificamente no ano de 1910, ou melhor, a imagem passada através dos jornais da época. De maneira mais objetiva, o jornal Folha do Acre dá um sentido enfático ao que está sendo vivenciado nesse momento descrito.

Não por acaso, nos questionamos sobre o sentido dado a essa narrativa e qual o interesse em tamanho "apelo" feito à Administração Departamental. Observamos no relato que as palavras iniciais são reveladas com a prontidão da ideia de "preocupação" com a sociedade, no entanto, as palavras finais do noticiário são "ponderadamente" carregadas de ironia e sarcasmo, onde "tudo parece avançar". Os jornais pesquisados idealizam e projetam toda uma afeição ao modelo que vinha sendo desenvolvido pela Administração Departamental do Alto Acre. Com essa convicção, encontramos em diversas passagens a "apelação" pública às autoridades, como pode ser observada na matéria "Pela moralidade pública", no sentido 
de intensificar os mecanismos de "controle", da "ordem", da "legalidade", da "disciplinarização" e da "moralidade". Concomitantemente, para o jornal Folha do Acre, o momento vivido é de suma importância para a propagação do discurso do "progresso", que chega às terras acreanas juntamente com a nova administração. Não obstante, os jornais carregam em suas páginas o poder de persuasão e de manipulação. E qual a melhor maneira de difundir e propagar os discursos? Ora, estamos falando de relações de poder, que estrategicamente oferecem ao leitor, ao seu público alvo, exatamente o que lhe é permitido acreditar.

O registro que passa a ter a nova Administração Departamental do Alto Acre, em grande medida deve-se aos registros jornalísticos. Os imaginários coletivos propostos pelos jornais intensificavam o "desejo" que se tinha pelo "progresso" da região. Dessa maneira, temos, por um lado, as autoridades locais enquadrando os sujeitos com base na disciplinarização dos espaços e, por outro, a imprensa difundindo o discurso do "progresso", da "modernidade" e da "higienização". Não é difícil compreender que o "progresso material e intelectual", destacado pelo jornal, requer das autoridades locais a repreensão e o castigo aos praticantes de desordens e delinquências. O "apelo" do jornal se faz na direção de que as autoridades tomem medidas de melhoramento no distrito de Empreza, tendo em vista prioritariamente os "sagrados princípios da moral e do decôro social", conforme enfatiza o noticiário.

Em 14 de agosto de 1910, o jornal Folha do Acre em sua primeira edição destacou a atuação e a grande importância que este meio de comunicação tinha junto à sociedade acreana em meados do século XX. Os primeiros anos do Território Federal do Acre, mergulhados na tentativa de "civilizar" o espaço e seus moradores, caminharam lentamente rumo ao "progresso". O referido jornal enfatizou "sutilmente" o exercício ao qual se comprometia com a sociedade acreana: "a Folha do Acre é o órgão das aspirações e dos ideaes do povo acreano. É o espelho límpido em que se reflectirão todas as suas necessidades, é o interprete fiel de suas alegrias e de suas maguas" (FOLHA DO ACRE 14/8/1910, p. 1). Nesse trecho, observamos o sentido passado através de suas "atraentes" palavras de "confiança". O jornal toma para si a responsabilidade de toda 
a reflexão das necessidades do povo acreano, informando que "por estas columnas defenderemos a sua cauza, pugnaremos pelo seu progresso e pela sua liberdade, pelo seu engrandecimento material, moral e intellectual" (FOLHA DO ACRE 14/8/1910, p. 1). Sob a influência do periódico, destacarmos a "advertência" apresentada pela editora:

Somos políticos, mas a nossa política é a politica larga, desinteressada e expontanea que só visa o interesse commum, o bem da colectividade, promovendo em seu seio a paz e a concordia, confraternizando todos os elementos na animadora expectativa de dias mais felizes. Condemnamos todos os excessos, a demagogia desenfreada e mais perigosa do que a guerra manifesta contras o bom publico. Não desceremos jamais a rastejar pelo lado dos ódios pessoaes e das paixões dissolventes. Mergullaremos a fronte na límpida claridade dum horizonte suave e puro onde só haja luz e só se escute o hymno da paz e do amor (FOLHA DO ACRE 14/8/1910, p. 1).

O jornal Folha do Acre (Órgão dos Interesses do Povo - Propriedade de uma Associação), esteve em circulação de 1910 a 1946. Nesta pesquisa, foram utilizadas as edições de 1910 a 1920. Theophilo Maia (Diretor) e Nelson Noronha (Secretário) fizeram parte da primeira administração editorial do jornal. Em 7 de maio de 1911, na edição número 36, Nelson Noronha passa a ser diretor e Gentil Noberto, redator- chefe. Ainda no ano de 1911, na edição número 51, ocorre uma mudança geral, a saber: Coronel Rodrigo de Carvalho (presidente), João d“'Oliveira Rôla (vicepresidente), Silvino Coelho da Sousa ( $1^{\circ}$ secretário), Francisco Cypriano d"Oliveira ( $2^{\circ}$ dito), Sebastião Francisco de Mello (tesoureiro), Joaquim Domingos Carneiro (diretor), Antônio Vieira de Sousa (diretor), Daniel Ferreira Lima (diretor). A terceira administração, apresentada ao publico leitor, permaneceu até a edição 201, veiculada em 23 de maio de 1915. Ao todo, foram 114 edições, o número mais representativo em quantidade em uma administração. A administração de Martinho Pinto e do Tenentecoronel Nelson Noronha (ambos diretores) e do administrador técnico João Rodrigues Sandes, aconteceu até a edição número 253. A última administração a que nos interessa fazer referência pela duração até o ano de 1920, foi a de A. Ferreira Brasil (diretor) e de Antônio Paulino (gerente- administrador), que esteve à frente até a edição número 340, de 30 de dezembro de 1920. Em suma, foram coletadas nas 239 edições 
pesquisadas, 6 matérias envolvendo o tema da prostituição ou seus sujeitos. Sendo 1 (um) na administração do diretor Theophilo Maia, 4 (quatro) nas edições de Nelson Noronha, 1 (um) na administração do Dr. Martinho Pinto e Tenente-coronel Nelson Noronha. Apesar de apresentarmos um número consideravelmente pequeno de matérias em relação à quantidade de edições pesquisadas, pudemos dialogar criteriosamente com as possibilidades que nos foram permitidas a partir do material coletado.

Em meio a tais descrições, apontamos uma imagem do contexto do Território Federal do Acre, conforme destaca Costa, a partir do Decreto $\mathrm{n}^{\mathrm{o}}$ 5.188, de 7 de abril de 1904:

Assim organizado o território, administrativa e judicialmente privados seus habitantes de todos os direitos, dos mais elementares direitos cívicos, como se fossem selvagens, ferropeados por impostos excessivos, nova espécie de prestamos dos grandes republicanos, os departamentos tornaram-se verdadeiras vaivodias, com seus soberanos - os prefeitos... As reclamações não podiam deixar de surgir. E surgiram, aqui e ali, nem sempre de caráter pacifico, dentro dos limites de ordem. Essa situação, capaz de justificar os maiores excessos populares, começou a repercutir no pais, e a imprensa e o Poder Legislativo se fizeram os interpretes desses clamores (COSTA, 1973, pp.148-149).

De acordo com a historiografia, o Departamento do Alto Acre, com sede inicialmente em Vila Empreza, foi administrado nos seus primeiros anos pelo prefeito Raphael Augusto da Cunha Mattos, que esteve na prefeitura entre o período de 1904 a 1906. Em seu Relatório, apresentado ao Sr. José Joaquim Seabra, Ministro da Justiça e Negócio Interiores, destaca os trabalhos feitos no Alto Acre de 17 de agosto a 31 de dezembro de 1904. Nota-se que o relatório intensifica a extraordinária necessidade de "civilização", que o lugar enquanto espaço público requer. Mattos destaca minuciosamente a situação em que se encontra o Território Federal do Acre, mais especificamente o Departamento do Alto Acre. Nessa sequência, sigamos a narrativa de Mattos, sobre a Villa Rio Branco, que o prefeito apresenta como sede provisória da prefeitura:

A villa Rio Branco, sede provisória do Governo da Prefeitura, tem 204 habitantes; 129 homens e 75 mulheres; sabem ler e escrever 50 e são analfabetos 154. Naturaes do Ceará 124, do Rio Acre 29, do Rio Grande do Norte 17, do Pará 6, da Parahyba 6, do Amazonas 5, do Maranhão 3, de 
Pernambuco 3, de Sergipe 2, do Rio Purus 1, do Piauhy 1, de Alagoas 1, da Bahia 1, de S. Paulo 1, da Itália 3 e do Peru 1; sejam 200 brasileiros e quatro estrangeiros (MATTOS, 1905, p. 113).

No "Regulamento da Secretaria da Prefeitura do Alto Acre", anexado ao Relatório da Prefeitura do Departamento do Alto Acre relativo ao período decorrido entre 18 de agosto e 31 de dezembro de 1904, observase no seu Art. $1^{\circ}$ os seguintes empregados da prefeitura: 1 secretário, 1 médico, 1 engenheiro, 1 agrimensor, 2 amanuenses, 2 praticantes, 1 porteiro, 1 continuo e 2 serventes. Interessa-nos, nesses dados, a figura médica os seus deveres, conforme podemos observar no excerto a seguir:

Art. 6. ${ }^{\circ}$ Compete ao médico:

$\int 1 .^{\circ}$ Encarregar-se de todos os estudos relativos ao saneamento e à hygiene do Departamento, na parte concernente á medicina.

$\int 2 .^{\circ}$ Formular boletins contendo conselhos de hygiene ao povo, a fim de serem publicados na imprensa e distribuídos por todo o departamento.

$\int 3 .^{\circ}$ Proceder a visitas domiciliarias a propor o fechamento das casas, tanto publicas como particulares, que não satisfaçam as condições de hygiene precisas.

$\int 4 .^{\circ}$ Examinar, tanto ao chegarem como nas próprias casas do negocio, todos os viveres e bebidas destinadas ao consumo da população.

$\int 5^{\circ}$ Praticar a vacinação e revacinação contra a varíola e organizar os socorros públicos necessários para evitar a invasão de moléstias transmissíveis.

$\int 6{ }^{\circ}$ Proceder ao isolamento e á desinfecção das casas onde ocorrerem moléstias contagiosas e providenciar sobre a remoção dos doentes para locaes que tenha previamente escolhido.

$\int 7 .^{\circ}$ Compete ao médico, finalmente, prestar informações sobre todos os assumptos que, de qualquer forma, interessem à saúde publica (MAT'TOS, 1905, pp. 26-27).

Inevitavelmente, através da idealização do prefeito concedido, fora imposta toda uma regulamentação, inclusive das práticas cotidianas. Nessa linha de pensamento, o investimento na figura médica remete similarmente ao ocorrido na Capital Federal. O saneamento e a higiene eram considerados necessários, e, em consequência da aprovação do Código de Postura, em 12 de dezembro de 1904, a presença médica se fez com maior "eficiência" e "firmeza". Em 23 de fevereiro de 1913, quase uma década após a publicação do Decreto no 13 , o jornal Folha do Acre noticia, em primeira página, sob o título "A hygiene das casas", um apelo 
à comunidade do Departamento do Alto Acre (Figura 1). Para o jornal, a higienização pública era um dos assuntos que exigiam imediatos cuidados. A cidade que nascia, destacada no noticiário, encontrava-se em formação, e é utilizada como alerta, enfatizando em todo o texto a necessidade de obedecer um plano e critérios de construção, no intuito de evitar "os aspectos desagradáveis nas construcções e ao mesmo tempo a falta de segurança e de condições sanitárias, será um erro que vem prejudicar imensamente o interesse que os habitantes da cidade devem ter de vel-a formar-se com todos os requisitos de beleza e solidez". A ênfase dada a preocupação estética e visual esclarece em grande medida a incisiva crítica à organização do espaço. Dos moradores que fazem parte desses espaços é igualmente exigida uma conduta de comportamento. Com o discurso "patriótico", o editorial reforça que tais medidas são pelo bem necessário do espaço público. Certamente, o desejo dos pequenos grupos políticos em reconstruir o lugar "civilizado" implicam naqueles que vivem a ameaçar a "ordem" através dos seus corpos e suas práticas.

Em conformidade com os discursos sanitários, segue o "apelo" do jornal Folha do Acre:

Temos ainda velhos pardieiros a desabar, barracas inhabitaveis, dentro do perímetro urbano, dando à cidade à feiura duma desmoronada aldeia e empatando a vista das construções novas. No districto da Empreza, bairro África, existem barracas situadas junto ao barranco do rio, que estão a exigir demolição urgente, para que não continuem a deixar a quem chega a bordo dos vapores que vem de Manaus e Pará a triste impressão de aportar a uma terra de pardieiros infectos e em desmoronamento. Urge que desapparecem d"alli esses entulhos e que a cidade pouco a pouco embora, se transforme para servir condignamente de capital do Departamento (FOLHA DO ACRE, 23/2/1913).

O editorial não dá ao certo o autor do noticiário. Sem mais informações, sabemos apenas que a narrativa "A hygiene das casas" foi publicada na edição número 106 do ano de 1913. A narrativa apresenta situações que muito se aproximam do Decreto estabelecido em 1904. Havia, nesse período, todo um aparato mediante as regras, as normas e o ordenamento no geral. $\mathrm{O}$ art. $6^{\circ}$ do "Codigo de postura da Intendencia do Xapury” é bastante claro e objetivo: "Os infractores das presentes posturas 
pagarão a multa de 200 \$ por infracção, e o dobro no caso de reincidência." Dessa maneira, o que o jornal Folha do Acre destacou na capa do seu número 106 já era recorrente desde os primeiros anos do século XX.

É necessário atentarmos à leitura do Regulamento da Secretaria da Prefeitura do Alto Acre, no parágrafo segundo, que diz: "Formular boletins contendo conselhos de hygiene ao povo, afim de serem publicados na imprensa e distribuídos por todo o departamento." Tem-se aqui um importante detalhe: a relação política e imprensa. Observemos que há uma regulamentação em 1904, projeto sistemático que implica diretamente na “união", ou melhor, na necessidade de haver na imprensa noticiários sobre tais questões. Em outras palavras, era dever do médico do Departamento do Alto Acre apresentar boletins nos jornais, modelando, doutrinando, enquadrando corpos, dentro de um formato que o regime político acreditava ser civilizador. O olhar doutrinário, atribuído à linguagem adotada, expressa intrinsecamente o valor dado aos princípios éticos e morais no cotidiano do Território.

O Código de Postura evidencia a preocupação existente com aqueles que por alguma razão descumpriam o ordenamento, permitindo-nos chegar a seguinte conclusão: toda e qualquer forma de enquadramento dos sujeitos era válida. Isso se aplicou à "construcção de casas", "limpeza publica", e "ordem e segurança dos habitantes". Assim, rigidamente, são aplicados o "progresso" e a "civilização". E em contrapartida, o não cumprimento desse Código acarreta o que pode ser observado do Artigo $\mathrm{n}^{\circ} 7$ ao $\mathrm{n}^{\circ} 20$ :

Art. 7. ${ }^{\circ}$ É prohibido depositar, ou atirar em logares públicos, lixo, garrafas, papeis e outros quaesquer materiaes.

Art. 8. São obrigados os moradores a manter o máximo asseio nas cass que habitarem e nos respectivos quintaes.

Art. 9. ${ }^{\circ}$ São responsáveis os proprietários pela limpeza das ruas, na parte correspondente ás suas casas.

Art. $10{ }^{\circ}$ É prohibido a criação de porcos, dentro da área urbana da villa.

Art. 11. ${ }^{\circ}$ É igualmente prohibido depositar borracha, sernamby e materiais inflamáveis dentro ou debaixo das casas de moradia.

Art. $12 .^{\circ}$ Os infractores das presentes posturas pagarão a multa de $100 \$$ por infracção e o dobro no caso de reincidência.

Art. 13. ${ }^{\circ}$ A ninguém é permitido andar armado dentro da villa. Multa de $50 \$ 000$. 
Art. $14{ }^{\circ}$ Não poderão as casas commerciaes ter as portas abertas além das 10 horas da noite, salvo licença da Intendencia. Multa de $100 \$ 000$.

Art. $15 .^{\circ}$ Todo preso da cadeia municipal pagará $50 \$$ de carceragem, na occasião de ser posto em liberdade, sob pena de ficar detido por mais de 48 horas.

Art. 16. ${ }^{\circ}$ É prohibido dar tiros dentro da zona urbana ou suburbana da villa, multa de $50 \$ 000$.

Art. 17. ${ }^{\circ}$ Todo aquelle que puzer armadilhas em caminho frequentado, ou dentro da zona da villa, pagará a multa de $200 \$$ e perderá o direito á arma.

Art. 18. ${ }^{\circ}$ É prohibido tomar banho na fonte que abastece de agua a villa. Multa de $50 \$ 000$.

Art. 19. ${ }^{\circ}$ É igualmente prohibido fazer qualquer plantação nas praias limítrofes da villa.

Art. 20..$^{\circ}$ Por animal que for encontrado vagando nas ruas, cavalar ou vacum, pagará o respectivo a muita de $50 \$ 000$ (MATTOS, 1905, p. 113).

Há que se ressaltar ainda que o Relatório da Prefeitura do Departamento do Alto Acre foi estruturado e construído em quatro meses da gestão de Raphael Augusto da Cunha Mattos. Na proporção em que vamos lidando com nas narrativas do Relatório, observamos os diversos problemas destacados pelo então prefeito, levando os sujeitos a acreditar e confiar plenamente na radical intervenção disciplinadora que ele pretendia realizar. Via-se, então, no espaço público, o reduto da criminalidade e do atraso cultural e social. Quanto à criminalidade no Território Federal do Acre, foi estabelecido pelo prefeito Raphael Augusto da Cunha Mattos rigorosas medidas disciplinadoras, conforme o Relatório destaca dos Artigos $13^{\circ}$ ao $20^{\circ}$, aplicadas aos diversos sujeitos, cuja índole era medida a partir dos estereótipos e do descumprimento das normas estabelecidas. Como já dito, temos como dimensão a caracterização dos sujeitos (da maneira como eram retratados e produzidos pelos periódicos da época), que em grande medida eram acusados/praticantes de "furtos", "ociosos", "vagabundos", "criminosos" e "prostitutas".

\section{Olhar disciplinador: representações de narrativas sobre prostituição}

A prostituição, enquanto problema social e político, "aprisionada a uma representação imaginaria" (RAGO, 1985, p. 61), retratada nos periódicos reflete-se consideravelmente na maneira como passa a ser 
vista pelos moradores. Em 07 de maio de 1911, o jornal Folha do Acre destaca, na coluna Cadastro Policial, o ocorrido no famoso botequim do Departamento do Alto Acre, o "Pau de fogo", dessa vez envolvendo três "horizontaes" de nomes Beatriz Bisleri, Lili Cadini e Antônia Barrabás, relatado da seguinte maneira:

Os fretadores da lancha Silvério Nery, sr. Fernandes \& $C^{a}$, segunda- feira ultima, andaram ás voltas com o pratico d'essa embarcação, Sr. Euzébio Galvão de Caldas, arvorado a commadante. Os tripulantes da Sylverio Nery, por sua vez tentaram jogar as cristas com o Ozebio. Para por termo a essas continuas desintelligencias, os srs. Fernandes \& $\mathrm{C}^{\mathrm{a}}$ convidaram o improvisado commandante a deixar o exercício d’essas altas funções. Accedendo ao convite, Ozebio metteu no cobre que lograra saldar e passou um recebido dando plena e geral quitação aos fretadores da Silveira Nery. Cahiu, porém, na esparréia de entrar no botequim Pau de fogo, onde se reúnem as mais chics abelhas da cidade, e... ficou na chinella. No dia seguinte pensou como obter mais plata e por mais que puchasse pela imaginação só encontrou um meio: fazer os srs. Fernando \& $\mathrm{C}^{a}$ escorropicharem mais dinheiro, sob pena de serem perseguidos pela Capitania do Corpo. Achou prudente que devia antes de tudo levar uma queixa à polícia e assim fez. $\mathrm{O}$ tenente Paes Barreto, delegado de polícia, syndicou do facto e depois de apurar a verdade, por um triz não metteu Ozebio nas grades. Por questões de paga não paga, as horizontaes Beatriz Bisleri, Lili Cadini e Antonia Barrabás, andaram pela polícia, onde quasi se diplomavam, mediante os trinta fachos que o carcereiro Fernandes não dispensa. D"outra vez é certo obterem os respectivos e almejados diplomas (FOLHA DO ACRE, 7/3/1911, p. 2).

Beatriz Bisleri, Lili Cadini, Antônia Barrabás, Maria Julia, Preta Bibiana, Doninha, Emília Rodrigues de Moraes, Amélia Pinto, Mayote e Izabel Ferreira são algumas das "personagens" encontradas nas narrativas dos jornais coletados. Envolvidas em grande parte em contendas, confusões e desordens, as narrativas sobre estas mulheres estamparam diversas páginas policiais dos jornais Folha do Acre e Commercio do Acre. Pensar as representações em torno da prostituição presentes nas narrativas dos editoriais dos referidos periódicos, que estiveram em circulação no Departamento do Alto Acre, se fez pela possibilidade de reflexão existente nas narrativas. O período específico se dá em relação ao momento pelo qual a Amazônia acreana estava passando, o novo regime organizacional que trouxe consigo uma nova "concepção" de mundo, uma busca desenfreada pelo "progresso"; em contrapartida, junto com essa 
percepção, veio a exclusão de diversos sujeitos sociais, cujas práticas eram acusadas de não estarem enquadradas no novo modelo organizacional.

Convém, entretanto, ressaltar que a noção de representação aqui aplicada, não se refere a uma mera representatividade do "real", visto que, as representações estão implicadas num "sentido mais particular e historicamente mais determinado". Chartier fornece a dimensão dessa dualidade (representação x real), como modelo de assimilação da representação de uma dada realidade, que acreditasse ser a permitida, ou que se faz ser permitida, entendendo que "todas elas tem em vista fazer com que a identidade do ser não seja outra coisa senão a aparência da representação, isto é, que a coisa não exista, a não ser no signo que a exibe" (CHARTIER, 1990, p. 20).

A problemática das representações, para Chartier, noção discutida desde o Antigo Regime, é um sentido produzido historicamente. Essa problemática "moldada através das series de discursos que o apreendem e o estruturam, conduz obrigatoriamente a uma reflexão sobre o modo como uma figuração desse tipo pode ser apropriada pelos leitores dos textos (ou das imagens), que dão a ver e a pensar o real" (LARROSA, 2014, pp. 23-24).

Observemos, portanto, no jornal Folha do Acre, de $1^{\circ}$ de janeiro de 1911, a utilização das palavras "desabusada", "abelha" (mulher solta, livre), referente à Maria Julia, e "divertidas", nesse caso, em referência a Joanna Bezerra de Araújo e a Benta Maria da Conceição, consideradas meretrizes, pelo jornal Folha do Acre. A página policial, assim destaca:

Perante o Sr. Dr. Juiz de direito, prestou affirmação do cargo de $1^{\circ}$ supplente de delegado auxiliar do Xapury, por intermédios do seu procurador advogado José Alves Maia o cidadão João do Figueiredo, que já entrou no exercício daquelle cargo.

- A desabusada abelha cancellista Maria Julia quis passar um natal turbulento na Empreza e assim foi parar na mucura, donde só sahiu no dia seguinte.

- João Sant"Anna tentou disparar um revolver no frontespicio de Maria Prego, vulgo Madame Tracajá. Resultado: a polícia agarrou-o e fel-o ir bater com os costados nas grades do xilindró.

- O delegado auxiliar passou um formidável pito nas divertidas Joanna Bezerra de Araujo e Benta Maria da Conceição que andaram aos supapos no hotel Madrid. O motivo da rixa entre as duas opportunidades foi a planta de um boliviano balúdo. O mellista Olynto d"Alva Barbalho tauto assoulhou 


\section{ARTIGO}

um terrível boato contra a vida dos principaes auctoridades militares deste departamento, que foi direitinho para o xadrez, fazendo alli preleccões sobre a influência do álcool nas concumitancias do organismo. Que diria o velho Zé-de-Melo de ouvisse (FOLHA DO ACRE, 1/1/1911, p. 3).

Segundo Larrosa, "as palavras não tem sentido próprio" (2014, p. 57), elas são apenas um corpo e, a partir dessa formulação, é dado a elas um sentido, mas isso não significa necessariamente um menor peso carregado por essas palavras, pois a partir dos sentidos dados a elas e de suas representações, elas passam a ter significados tanto quanto foram destinadas. Nessa convicção, para Larrosa,

as palavras produzem sentido, criam realidades e às vezes funcionam como potentes mecanismos de subjetivação. Eu creio no poder das palavras, na força das palavras, em que fazemos coisas com as palavras e também que as palavras fazem coisas conosco. As palavras determinam nosso pensamento porque não pensamos com pensamento, mas com palavras, não pensamos baseando-nos em nossa genialidade, em nossa inteligência, mas valendo-nos de nossas palavras. E pensar não é somente "raciocinar" ou "calcular" ou "argumentar", como nos tem sido ensinado algumas vezes, mas é sobretudo dar sentido ao que somos e ao que nos acontece. E isto, o sentido ou o semsentido, é algo que tem a ver com as palavras (LARROSA, 2014, p. 152).

Fazendo uma leitura das narrativas dos jornais de circulação do início do século XX, nos deparamos com alguns casos onde se verifica a questão levantada por Larrosa, isto é, o sentido dado às palavras. Não em qualquer contexto, ou em qualquer narrativa jornalística, mas especificamente naquelas envolvendo as dimensões simbólicas sobre as mulheres acusadas de exercerem a prostituição no Departamento do Alto Acre.

Refletindo ainda sobre as questões que permeiam esta discussão, nos deparamos com o pensamento de Rago, apresentado em seu livro, Do cabaré ao lar: a utopia da cidade disciplinar, Brasil 1890-1930, em que essa necessidade de aplicar os "desejos" de lugar, mesmo se apresentando em forma de "invenção", vem sendo constatada no Brasil desde o século XIX. Essa busca de controle insaciável sobre uma possível, "desestabilização da ordem social, ameaça de caos, naufrágio da vida civilizada" (RAGO, 1985, p. 11), pretende em si formar uma identidade "moralizada", como afirma 
a autora, banindo todo e qualquer comportamento desviante, ameaçador e impuro.

As possibilidades de reflexão nos levam a dialogar sobre as imagens projetadas a partir desses sujeitos "desviantes" e "indesejáveis", que assumem uma posição em relação às normas disciplinadoras manifestadas pelas estratégias de enquadramento. Nesta lógica, a prostituição opunhase a essa normalização dos espaços e torna-se foco da necessidade de ordenamento e do discurso médico, que, atrelado à ideia de "degradação física e moral", determina e redefine um ideal de espaço. Os códigos de conduta passam a refletir o idealizado pelas autoridades, instituindo

hábitos moralizadores, costumes regrados, em contraposição às práticas populares promíscuas e anti-higiênicas observadas no interior da habitação operária, na lógica do poder significava revelar ao pobre o modelo de organização familiar a seguir. Nesta utopia reformadora, a superação da luta de classes passava pela desodorização do espaço privado do trabalhador de duplo modo: tanto pela designação da forma da moradia popular, quanto pela higienização dos papeis sociais representados no interior do espaço doméstico que se pretendia fundar. A família nuclear, reservada, voltada sobre si mesma, instalada numa habitação aconchegante deveria exercer uma sedução no espirito do trabalhador, integrando- o universo dos valores dominantes (RAGO, 1985, p. 61).

A prostituição vista e "classificada pelo saber médico e criminológico como "vício", "fermento corrosivo" lançado no grêmio social, que "tende a alastrar-se e a corromper todo o corpo social", já direciona o posicionamento e o pensamento crítico das autoridades no início do século XX. Outra questão levantada por Rago implica no pensamento médico voltado à associação trabalho x prazer. A inviabilidade de ser associada a um trabalho "qualquer", foi a questão levantada pelos estudiosos da época sob esse discurso, de modo que a prostituição reaparece com objetivo principal, de "satisfação do prazer e, nesta lógica, prazer e trabalhos são categorias antinômicas" (RAGO, 1985, pp. 85-90). Diversas eram as questões para segregar as praticantes da prostituição.

A configuração que a prostituição passa a ter, enclausurada a esse enquadramento social, cultural, econômico e político, resulta normalmente de ações excludentes, classificatórias e conceituais. As narrativas jornalísticas do Território Federal do Acre traduzem essas mulheres 
em relação às ações de desordem, dessa maneira, elas passam a ter uma visibilidade mínima, isto é, aparecem a partir de sua inserção no espaço público e por intermédio de suas práticas.

Em uma análise um tanto superficial (pois essa não era a abordagem deste estudo), percebemos a inserção da figura feminina no espaço público, conforme era tratada pelos periódicos pesquisados, um tanto precária. Nosso olhar às narrativas de prostituição não nos permitiu trazer dados concretos sobre essa relação da figura feminina e sua participação no espaço público no início do século XX. Já as prostitutas (apesar de estarem dentro do gênero feminino) são visualizadas apenas enquanto instabilidade da nova e planejada moralidade pública. As narrativas dos jornais do período territorial trazem esses sujeitos apenas com o objetivo de repreender suas ações, mostrando a todos que as "práticas condenáveis" dessas mulheres deveriam ser evitadas.

As possibilidades de instauração de um novo espaço público, atrelado às "manifestações" que a imprensa noticiava, tornavam "necessária" essa intervenção que os editoriais tanto clamavam às autoridades competentes, "agindo de acordo com o sentir do público, reprimam o abuso, castigando os delinquentes para que não reproduzam a prática de suas acções condemnáveis, dos actos que os tornam passiveis, das penas estatuídas pelas leis asseguradoras de decoro social da moralidade pública" (FOLHA DO ACRE, 20/9/1910, pp. 1-2), dizia o jornal Folha do Acre, na narrativa intitulada "Pela moralidade pública".

Atuando no Departamento do Alto Acre, o advogado Lourenço Moreira Lima, em setembro de 1916, fez uma denúncia contra o Juiz de Direito da Comarca de Xapury, João Paulo de Almeida Couto, direcionada ao presidente do Brasil Wenceslau Braz. Segundo os relatos da denúncia apresentada no jornal Commercio do Acre, o Juiz João Paulo de Almeida Couto não estava agindo de acordo com a ética que sua função requeria. Lourenço Moreira Lima, alegando os diversos atos condenáveis do juiz, não economizou nas acusações. Dizia que cotidianamente o juiz entregava-se aos vícios do Território, como jogos de azar e de frequentar casas proibidas. Assim, Lourenço destaca:

A incontinência publica e escandalosa, conforme a linguagem do Cod. Penal, 
em que vive o denunciado, constitue uma afronta ao pudor das famílias do Xapury. O denunciado, além de cohabitar com prostituta que é sua amazia, se faz della acompanhar ás casa de jogo, dando os maiores escândalos, como succedeu num dos mezes do anno findo, na tavolagem conhecida por Casa Branca, onde a alludida mulher lhe atirou ao rosto um punhado de fixas, resultando disso ter o denunciado esbofeteado e pisado a mesma, no meio da infernal algazarra que fazia a ralé ali presente. No dia seguinte o denunciado atravessava as ruas da cidade de braço dado com a sua amazia, ostentando tão degradante reconciliação (COMMERCIO DO ACRE, 24/9/1916, p. 5).

Nesta mesma edição do jornal Commercio do Acre, em "Notas policiaes" foi informada a apreensão da "horizontal" de Raymunda Alves Feitosa; sem muitas descrições, a prisão da aludida meretriz é justificada apenas pelo ato de "ofensa à moral". Esse jornal se autodenominava "de caracter comercial e que se destina à defesa dos interesses geraes desta região, occupando-se de tudo que disser respeito ao progresso do Acre" (COMMERCIO DO ACRE, 14/11/1915, p. 2) e esteve em circulação entre os anos de 1910 a 1919. Durante a pesquisa para levantamento de dados, coletamos 06 narrativas sobre prostituição entre 178 edições pesquisadas. Diante de algumas lacunas, foi possível realizar esse levantamento somente a partir das edições dos anos de 1915 a 1918, tendo em vista a disponibilidade do acervo na Hemeroteca Digital no site da Biblioteca Nacional. Romeu Ferreira e Rubens Thaumaturgo estiveram na administração editorial das edições pesquisadas. Sem identificação de "nomes", é apresentado apenas que diversos redatores e colaboradores fizeram parte do editorial do jornal Commercio do Acre, na referida época.

Pretende-se, por meio de tais descrições, afirmar que se tratava de um jornal voltado às discussões sobre o comercio territorial, mas entre outras questões apresentadas, trouxe consigo um teor crítico sobre a condição desses sujeitos desviantes da ordem e ameaça a moral. A repreensão da prostituição, enquanto prática condenável, atrelada à imagem de "sujeira” e "impureza" e também de "imoralidade", como indica o excerto: "pretende fundar um novo modelo normativo de feminilidade e convencer a mulher de que deve corresponder a ele" (RAGO,1985, p. 75).

Sob o título "Uma casa prejudicial", o Commercio do Acre, fez uma denúncia indireta às autoridades responsáveis, pedindo medidas cabíveis 
para as situações corriqueiras do Departamento do Alto Acre: "seria conveniente que a policia ordenasse o fechamento da 'Rapiocagem', para evitar a reproducção das scenas de desordem que ali se dão continuamente, com a bebedeira dos frequentadores" (COMMERCIO DO ACRE, $21 / 1 / 1917$, p. 2). A casa "Rapiocagem", localizada na rua Dr. Baptista de Moraes, curiosamente em frente à Delegacia de Polícia, era um dos lugares da "perdição", "um sórdido estabelecimento, onde se reúnem desoccupados e amigos do copo com meretrizes da mais baixa escala" (COMMERCIO DO ACRE, 21/1/1917, p. 2).

Segundo o editorial, o Sr. Pernambucano (responsável pela casa) frequentemente visitava a delegacia, acusado de aceitar desordem na casa, e consequentemente por ser testemunha rotineira de algazarras, brigas e contendas: "não raro praticavam-se desordens e o dono do estabelecimento, Fuão Pernambuco anda sempre as voltas com a polícia" (COMMERCIO DO ACRE, 21/1/1917, p. 2), afirmava o jornal, sobre as constantes idas do dono à Delegacia; "Alli se bebe até a imbriaguez, alli se canta e se dança, como se a vida fosse um continuo carnaval" (COMMERCIO DO ACRE, $21 / 1 / 1917$, p. 2.), indignado alarmava o noticiário nos primeiros de dias de 1917. Ainda sob esta perspectiva, observemos outro ocorrido relatado pelo periódico Commercio do Acre. O noticiário intitulado "Cobija" se inicia ironicamente da seguinte maneira:

Julgo-me feliz por achar-me já em um Paiz livre e onde o tyrannizado pode chorar suas maguas, graças ao grau cívico d"este povo e ao programma do vosso independente periódico! Em maldita hora, tive que desviar-me temporariamente da crize comercial que cercava meus negócios nesta cidade, para o alto Acre, onde em Cobija vi a minha vida cercada por uma crize moral, cívica e social (COMMERCIO DO ACRE, 21/1/1917, p. 2).

Esclarece indignado o Sr. Sebastião Asséf que, ao chegar na cidade de Basiléia, hospeda-se na casa de um amigo, local em que venderia seus objetos de miçanga, em decorrência de uma grande crise nos comércios do Alto Acre. Ali apareceu a meretriz conhecida por "Mamão", que, segundo Asséf, comprou alguns objetos, tendo deixado, porém, uma quantia significante para ser paga no dia seguinte. Eis o motivo de tamanha 
indignação de Assef, que não hesitou em estampar tal ocorrido na folha editorial.

Tempos depois, com intenção de retorno, foi despedir-se dos amigos mais próximos, na certeza de conciliar tal atitude às cobranças necessárias. Recebido com diversos insultos pela meretriz "Mamão", Sebastião Asséf não ousou em lhe dar um empurrão. "Mamão", ao levantar-se, apresentou um enorme punhal, motivo pelo qual ambos foram conduzidos à policia para averiguação:

E eu prompto para pagar la mulita e depois ver a Mamão processada por crime de tentativa de assassinato, pois, mal sabia que o honrado comissário era abogado ardente de la mujer e que era preciso que eu prestasse fiança para obter a minha liberdade e depois constituir advogado e arranjar testemunhas para provar a minha inocência d"accuzação feita por Mamão de que sou contrabandista, apresentando ella como testemunha, duas suas colegas, cujos depoimentos foram tomados no mesmo dia pelo Melgarejo de la aduana Sr. Pombek, e eu para debater tal calumnia apresentei oito testemunhas, de negociantes honestos, inclusive a de quem deu passagem a Mamão quando ettravessou de Brazilea á Cobija com o embrulho dos malditos objectos na mão, e com o consentimento del guardia Rafael, e o honesto Pomberk, só depois de 18 dias de massadas e venalidades escandalosas é que se resolveu a tomar os depoimentos, a sabe Deus como, porque uma das testemunhas notando a bandalheira, protestou recuzando assignar ou reconhecer um depoimento completamente diferente do que déra, resultando uma forte discussão com o Melgarejo! E o meu advogado parecia-me que temia as consequências, porque nenhum protesto fez contra tantas venalidades; fazia apenas o papel d"um armênio (COMMERCIO DO ACRE, 14/11/1915, p. 2).

Outra narrativa a ser descrita é a da mulher identificada por "Preta Bibiana", que na noite de 30 de março de 1916, por "offensa” à moral pública, foi parar no xadrez. A meretriz estava a passar em frente da porta de um açougue, localizado no "Mangueira", local em que proferiu palavras ofensivas ao dono do estabelecimento. O noticiário não apresenta ao leitor o contexto do ocorrido, não sabemos o que provocou tal atitude da meretriz "Preta Bibiana", assim como não descreve as ações do encarregado do açougue, o que gera inúmeros questionamentos. A narrativa não traz nenhuma informação sobre a meretriz, a não ser a sua recorrente prática de desordens. Dá a entender, ou melhor, o editorial faz entender, na sua sutileza, que o dono do estabelecimento, de nome não identificado, vítima 
da meretriz, não ousou agredi-la verbalmente. A informação revela apenas a acusação da meretriz. Ou seja, em outras palavras, o jornal informa que "Preta Bibiana", sem nenhum motivo e sem nenhuma razão, saiu proferindo palavras ofensivas a um inocente comerciante.

Os jornais não dão ao certo informações sobre quem eram essas mulheres, nem suas idades, local de residência, descrições sobre suas famílias ou escolaridade. Sabemos apenas que elas frequentemente estampavam as paginas policiais, tachadas de desordeiras e ofensoras da moral. Na maioria dos casos, as descrições das acusações nas narrativas refletem apenas as ações dessas mulheres. De maneira violenta, os jornais transmitem um sentido peculiarmente agressivo e, em contrapartida, os outros "lados" das histórias não são vistos, não são apresentados. E são justamente essas as histórias que estampam algumas das páginas policias dos jornais analisados. Em suma, o olhar do editorial prevalece sobre tais situações, fazendo com que grande parte dos seus leitores passem a ver a prostituição e os seus sujeitos, apenas como sujeitos imorais, desordeiros, ociosos, ofensores e marginais.

Ação parecida ocorreu em 17 de setembro de 1916, desta vez, envolvendo a "horizontal Doninha":

Por questões de ciúmes esteve preso, o moreno, Cyrillo Borges, alfaiate, conhecido por "Dr. Agulha" que tentou retalhar com uma navalha, a sua amante Raymunda Chaves de Albuquerque, vulgo "Doninha". Por offensas a moral e desrespeito a autoridade de permanência, foi presa a horizontal "Doninha", que gramou apenas 15 horas no xadrez (COMMERCIO DO ACRE, 17/9/1916, p. 4).

Pensamos que outra questão que merece destaque é que nas narrativas coletadas nos periódicos do Acre Território, sem nenhuma exceção, não aparecem as falas, as vozes e as experiências das mulheres. Os relatos aqui discutidos sobre essas "mulheres da vida" sempre são relatos de "terceiros"; narradas por delegados, por policiais, e por escrivães, as narrativas sempre carregam um sentido doutrinário, justamente por ser esse o aspecto característico da imprensa acreana no período do início do século XX:

Agóra que a sociedade acreana se forma procuramos sobretudo conduzi- 


\section{ARTIGO}

la para um oriente rútilo e sereno onde reina a harmonia e imperam o bem, a moral e a virtude. Educar a família sob os princípios mais puro da civilização, fazer com que ella seja acatada e dignificada numa comunhão de ideas benéficas. Protegel-a, amparal-a - eis uma das nossas mais melindrosas preocupações (FOLHA DO ACRE, 14/8/1910, p. 1).

Vale notar que, em 19 de agosto de 1910, esse mesmo periódico propagava as mesmas advertências morais e éticas, no sentido de alertar às mulheres não-praticantes da atividade do meretrício a não terem tais condutas, prevendo situações desastrosas:

No bairro África desta cidade, mora a mulher do nome Emilia Rodrigues de Moraes, conhecida desordeira e inimiga da moral, que vem sofrendo as consequências do seu péssimo procedimento desde Manaos de onde a polícia a exportou por inconveniente aos foros da civilisações daquella capital, e que aqui repetidamente tem visitado o xadrez correcional. No dia 2 do corrente ano, às 3 horas da tarde, Emilia, depois de altercar com um criado pharmáceutico Sr. Sandoval Meire, começou a apitar chamando a polícia, enquanto almejava o seu adversário com um revolver que disparou contra o mesmo, não acertando felizmente o alvo. A criminosa foi immediatamente presa pelo Sr. Major Honório José Teixeira que a entregou á polícia que então compareceu no local apresentando-se alli duas praças e o respectivo sargento. Alguns momentos depois chegou também o Sr. Dr. Victorino d’Assunção, delegado auxiliar a quem foi entregue o revolver. Na repartição de polícia foi em seguida lavrado o respectivo auto de flagrante delicto. Ao chegar ao logar da ocorrência, sendo o Sr. Dr. Victorino desrespeitado por uma das praças que alli faziam o serviço policial, reagiu a autoridade determinando ao sargento que prendesse o insubordinado, ao que o mesmo tornou-se rebelde desautorando o Sr. Delegado. O Sr. Dr. Victorino da Assunção deu no dia seguinte a sua demissão do logar de delegado auxiliar sendo nomeado para substituil-o o senhor tenente Antônio Padilha. Nesse mesmo dia Emilia Rodrigues de Moraes foi posta em liberdade. A praça que desrespeitou o Sr. Dr. Victorino Assunção foi imposta a pena da expulsão da guarda-local, o sargento, porém, nada sofreu (FOLHA DO ACRE, 19/8/1910, p. 3).

\section{O $1^{\circ}$ de novembro de 1917, Folha do Acre destacou um fato ainda} não percebido nas narrativas anteriores. Trata-se do seguinte ocorrido, envolvendo uma mulher identificada por Júlia Maria dos Santos:

As $16^{1 / 2}$ horas do dia 28 do mez homtem findo, no beco da fabrica, á residência das mudanas senhorita Arruda e Julia Maria dos Santos, conhecida por Flagelada, Abdoral Lima, de 18 annos de idade, solteiro cearense, motorista empregado no seringal Catuabá tendo bebido com as referidas mudanças alguns grogs de cognac puxou o seu revolver Mauser; manejando-o 
contra Julia. Senhorita tomou a frente mas com tanta infelicidade que o fez precisamente quando a percussão do cartucho se verificava, recebendo assim, no braço o projectil que varando-o de lado a lado foi-se alojar na parte inferior da cavidade abdominal da inditosa Julia. Perseguindo pelo clamor publico, o delinquente foi preso em flagrante, na rua Plácido de Castro, próximo á rua Abunã. Confessou o crime. Populares conduziram Julia á Pharmacia Ocidental, onde uma hora depois, receberam os primeiros cuidados médicos. Julia Maria dos Santos falleceu antehomtem, às 22 horas (FOLHA DO ACRE, 1/11/1917, p. 2).

Contraditoriamente, o fenômeno da prostituição entendido enquanto "problema" e enfatizado, na maioria das vezes, como problema público, passa a estar intrinsecamente envolvido com o fator político do que mesmo com o social, visto que a propagação da prostituição intervém diretamente nos planos políticos da época. O fato notável aparece quando a prostituição deixa de ser vista apenas enquanto problema social e começa a ser um problema dos poderes públicos e/ou políticos, o que é marcadamente apresentado no Relatório do prefeito Raphael Augusto da Cunha Mattos, em 1904, ao tratar da erradicação da ociosidade, da vagabundagem, da prostituição, da sujeira e da criminalidade.

A percepção sobre as prostitutas, enquanto causadoras de desordens, tumultos e desentendimentos no Território Federal do Acre, resulta em grande medida de suas ações conforme registradas na escrita jornalística, da maneira como vimos trazendo desde o início desta pesquisa (e não há como não evidenciar este dado). Salientamos isto, pois as meretrizes, as mundanas, as abelhas, as horizontais, as mulheres da vida, qualquer que seja a nomeação dada a essas mulheres, estas existiram/existem e fizeram/fazem parte da sociedade, historicamente, dentro de um grupo específico, que se faz a partir de conceitos e características superficiais e estereotipadas, juntamente com outros sujeitos rotineiramente nomeados de "marginalizados".

As narrativas trazem sim, imagens, discursos, e símbolos sobre estes sujeitos, mas as prostitutas, "não são vítimas, nem objetos passivos de um discurso de poder, nem simples engrenagens de um dispositivo, nem chaves para compreender universos normativos em torno da sexualidade feminina" (SCHETTINI, 2006, p. 15). Considerar tais afirmações, seria um tanto 
redundante diante do diálogo que vimos construindo aqui, enfatizando que as experiências desses sujeitos não se resumem às meras narrativas estampadas nas "notas policias" dos periódicos, sendo o mesmo válido para as designações usadas para referir esses sujeitos: abelhas, mariposas, mundanas e etc., palavras que operam "como simples portador de seu sentido, como representante ou vicário, ou lugar-tenente de seu sentido, como o lugar que tem ou com-tém o sentido" (LARROSA, 2014, p. 178). O que nos inquieta são as representações dadas a essas mulheres, fazendo com que estejam associadas cotidianamente a tais questões, simplesmente reduzindo-as a ações contra a ordem e a moral que se tentavam estabelecer nesse período. Pensamos que, talvez, essas narrativas pudessem estabelecer um paralelo entre os sentidos historicamente produzidos e a apropriação desses significados, e, a partir disso, visualizá-las num processo histórico, além dos imaginários que nos são "permitidos". Daí a conclusão de que não se trata do que essas narrativas trazem em suas linhas, mas o sentido no qual é aplicado o imaginário e as representações.

Julia Maria dos Santos, Emilia Rodrigues de Moraes, Arruda, Preta Bibiana, Doninha e tantas outras, narradas pelo olhar disciplinador e doutrinário, não podem ser vistas, lidas e pensadas minimamente por manifestações registradas na escrita. Mas é a partir do "modo como as configurações inscritas nos textos, que dão lugar a séries, construíram representações aceitas ou impostas do mundo social" (CHARTIER, 1990, p. 24) que nos pautamos. Pensar que existiram outras histórias, outras verdades, outros sentidos, outras experiências, é nossa maior evidência. Visualizá-las dentro dessa convicção, permitiu-nos pensá-las num sentido transgressor: para além de corpos sexuais.

\section{Referências}

CHARTIER, R. A história cultural: entre práticas e representações. Trad. Maria Manuella Galhardo. Rio do Janeiro: Bertrand Brasil, 1990.

COMMERCIO DO ACRE. Rio Branco, 1915/1916/1917. Acervo da Biblioteca Nacional.

COSTA, J. C. A conquista do deserto ocidental: subsídios para a história do Território do Acre. 2. ed. São Paulo: Editora Nacional, Brasília, 1973. 
FOLHA DO ACRE. Rio Branco, 1910/1911/1913/1917. Acervo da Biblioteca Nacional.

LARROSA, J. Linguagem e educação depois de Babel. Trad. Cynthia Farina. Belo Horizonte: Autêntica Editora, 2014.

MATTOS, R. A. C. Relatório da Prefeitura do Departamento do Alto Acre relativo ao período decorrido entre 18 de agosto e 31 de dezembro de 1904. Anexo H. In: BRAZIL. Ministério da Justiça e Negócios Interiores. Relatório apresentado ao presidente dos Estados Unidos do Brazil pelo ministro Dr. J. J. Seabra. Volume II. Rio de Janeiro: Imprensa Nacional, mar. 1905.

MENEZES, L. M. Os indesejáveis: desclassificados da modernidade. Protesto, crime e expulsão na Capital Federal (1890-1930). Rio de Janeiro: EdUERJ, 1996. RAGO, M. Do cabaré ao lar: a utopia da cidade disciplinar: Brasil 1890-1930. Rio de Janeiro: Paz e Terra, 1985.

SCHETTINI, C. "Que tenhas teu corpo": uma história social da prostituição no Rio de Janeiro das primeiras décadas republicanas. Rio de Janeiro: Arquivo Nacional, 2006.

SILVA, F. B. Acre, a Sibéria tropical: desterrados para as regiões do Acre em 1904 e 1910. Manaus: UEA Edições, 2013.

Data de recebimento: 01/05/2018

Data de aceite: $30 / 05 / 2018$ 